\title{
Sensitive Stages in the Photoperiodic Determination of Wing Forms and Reproduction in the Water Strider, Aquarius paludum (Fabricius)
}

\author{
Tetsuya Inoue ${ }^{1}$ and Tetsuo Harada ${ }^{2 *}$ \\ ${ }^{1}$ Department of Biology, Faculty of Education, Kochi University, Kochi 780, Japan \\ ${ }^{2}$ Department of Biology, Faculty of Science, Osaka City University, Osaka 558, Japan
}

\begin{abstract}
The present work was performed to clarify the photosensitive stage for wing-form determination and reproduction in Aquarius paludum. Only $40-60 \%$ of the adults were long winged when they were reared under $12 \mathrm{hr}$ light-12 hr dark (12L-12D) during the first two instars and under 15.5L-8.5D during the rest of nymphal stage. However, all became long-winged, when they were exposed to 12L-12D until the end of the third instar. The exposure to $15.5 \mathrm{~L}-8.5 \mathrm{D}$ till the end of the third instar induced short-winged adults of less than $15 \%$, but long days until the fourth instar promoted about $40 \%$. The exposure to long days either during the third, fourth or fifth instar promoted brachyptery, whereas all became long-winged when they were reared under long days either during the first or second instar. The exposure during the fifth instar induced maturing oocytes. The results indicate that the photosensitive stage for brachyptery occurs from the third to the beginning of the fifth instar, whereas that for oocyte maturation occurs during the fifth instar. Such a difference may refute the supposition of the oogenesis-flight syndrome that the two factors are tightly linked.
\end{abstract}

\section{INTRODUCTION}

Water striders belonging to Aquarius, Gerris and Limnoporus frequently exhibit wing dimorphism (Andersen, 1993; Spence and Andersen, 1994). Aquarius paludum (Fabricius) produces both brachypterous and macropterous morphs, which are under photoperiodic control: long days throughout the development induce brachypters and reproduction, whereas short days throughout induce macropters and diapause (Harada and Numata, 1993). The critical day length for the determination of wing forms was, however, longer by about $45 \mathrm{~min}$ than that for the induction of adult diapause for the populations in Kochi, Japan. The nymphs of the first generation in Kochi develop in May and early June when the natural day length is longer than either of the two critical day lengths for wing-form and reproduction. The majority $(60 \%)$ become brachypterous and promptly begin to reproduce. The nymphs of the third generation develop in late September and October when the natural day length is shorter than the either of the two critical day lengths. Most of them become macropterous adults and enter diapause. The nymphs of the second generation develop in August and early September when the natural day length is between the two critical day lengths. Therefore, most of them become macropterous and promptly begin to reproduce, and a linkage between wing form and reproduction (short winged,

\footnotetext{
* Corresponding author: Tel. +81-888-44-8410;
} FAX. $+81-888-44-8410$. reproductive; long winged, diapause), supposed by oogenesisflight syndrome (Johnson, 1969; Harrison, 1980) is not seen for the second generation. However, a tight linkage between the photosensitive stages for wing form and reproduction has not been established.

The present study investigates the sensitive stages for the two photoperiodic phenomena in A. paludum to elucidate this linkage.

\section{MATERIALS AND METHODS}

Macropterous adults (Exp 1,2 and 4) of the second and third generations or brachypterous adults $(\operatorname{Exp} 3)$ of the first generation were collected from a pond or a waterway in Kochi, and they were reared under $15.5 \mathrm{~L}-8.5 \mathrm{D}$ at $20 \pm 2^{\circ} \mathrm{C}$ which promotes reproduction. Eggs laid by these females were kept under the same conditions. The first instar nymphs hatching from the eggs were used for the experiments. Fifteen to twenty individuals were reared in a plastic case $\left(34 \times 23.5 \times 4.5 \mathrm{~cm}^{3}\right)$ under different photoperiods at $20 \pm 2^{\circ} \mathrm{C}$.

A group of nymphs derived from the above females were reared under $15.5 \mathrm{~L}-8.5 \mathrm{D}$ until a specific instar and then transferred to $12 \mathrm{~L}$ $12 \mathrm{D}$, or vice versa (Exp 1 and 2). Another group of nymphs were exposed to $15.5 \mathrm{~L}-8.5 \mathrm{D}$ during one specific instar and to $12.5 \mathrm{~L}-11.5 \mathrm{D}$ (value close to the critical daylengths: 13L-11D for reproduction and 13.75L-10.25D for wing forms) during the other four instars (Exp 3 ). Still another group of nymphs were reared under 15.5L-8.5D only during one or two specific instars and under 9.5L-14.5D (far from the two critical daylengths) during the rest of the nymphal period (Exp 4).

At adult emergence, wing lengths were presented by relative lengths (wing index) to abdominal segments (Harada and Taneda, 1989), and classified as long-winged [females: (fore wing index, hind wing index $)=(11,9)$; males: $(12,11)$ ], semi-long winged [females: $(10,8),(11,8)$ or $(10,9)$; males: $(12,10)(12,9)$ or $(11,10)]$, or short 
winged [females: (7-4,1-2); males: (9-7,5-1)].

After adult emergence, a single male and female pair was transferred to a plastic pot ( $14 \mathrm{~cm}$ diameter; $5 \mathrm{~cm}$ depth) and reared either under 9.5L-14.5D (Exp 4), 12L-12D (Exp 1 and 2) or 12.5L$11.5 \mathrm{D}$ (Exp 3). The detailed rearing method has been reported (Harada, 1992, 1993). Oviposition was observed for the first 30 days of adult life (Exp 3 and 4). Adults were dissected at 30 days after adult emergence to determine the presence and number of mature oocytes (Exp 1-4). Adults which had more than one mature oocyte were judged as non-diapause adults, while those having no mature oocytes as diapause ones (Exp 3,4).

\section{RESULTS}

The exposure to $12 \mathrm{~L}-12 \mathrm{D}$ throughout the nymphal stage produced $100 \%$ long-wings, as did 15.5L-8.5D in the first instar, only (Fig. 1a,b). The exposure to 15.5L-8.5D until the second or third instar also induced a low percentage of short-wings, but caused a small percentage of adults to develop semi-long wings (Fig. 1c,d). The same exposure till the fourth instar, or later, produced many short-winged adults (Fig. 1e,f).

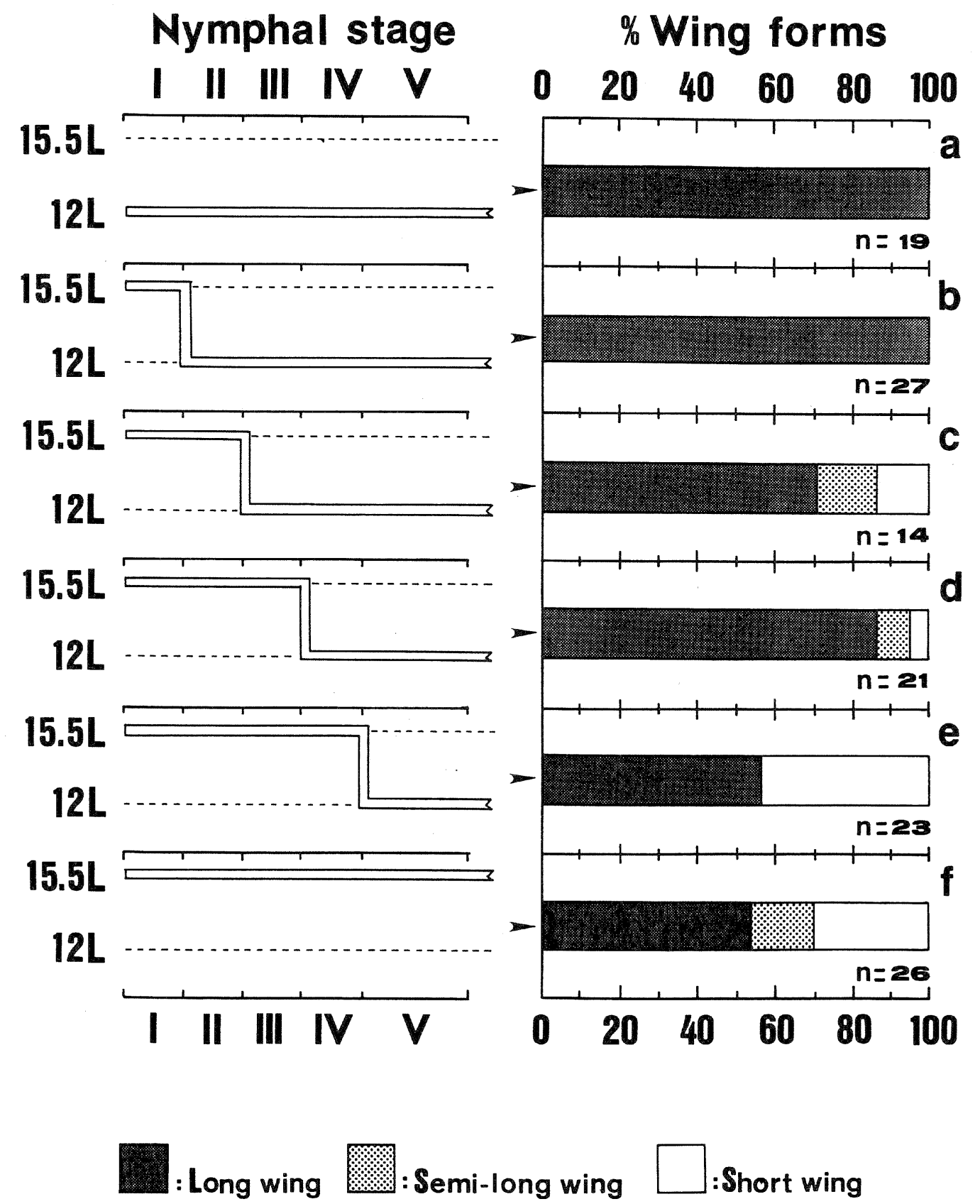

Fig. 1. Effect of transfer from 15.5L-8.5D to 12L-12D photoperiod during various instars on the induction of three wing-forms in $A$. paludum. Nymphs were transferred on the first day of new instars. Results of Fisher's exact probability test for the proportion of wing-forms: a versus $\mathrm{b}, \mathrm{c}$ or $\mathrm{d}, P>0.05$; a versus e or $\mathrm{f}, P<0.05$. 
Only $50 \%$ to $60 \%$ of the nymphs developed into the longwinged when they were placed under 12L-12D for the first one or two instars only, or under $15.5 \mathrm{~L}-8.5 \mathrm{D}$ throughout nymphal stage (Fig. 2a,b,c). All became long-winged adults, when they had been grown under 12L-12D until the end of the third instar or later (Fig. 2d,e).

The exposure to $15.5 \mathrm{~L}-8.5 \mathrm{D}$ during the first or the second instar produced no semi-longed or short-winged adults (Fig. $3 b, c)$ as did $12.5 \mathrm{~L}-11.5 \mathrm{D}$ through the whole nymphal stage
(Fig. 3a). The exposure to 15.5L-8.5D during the third (Fig. $3 d$ ) or fourth (Fig. 3e) instar induced small percentages of short-winged or semi-long winged adults. The exposure to 15.5L-8.5D during the fifth instar slightly increased the proportion of short-winged form (not significant of $P=0.051$ ). 15.5L-8.5D during one of the first to fourth instars failed to induce oocyte maturation in the majority of females (Fig. 3ae). However, about $80 \%$ of females, when the fifth instar nymphs had been exposed to $15.5 \mathrm{~L}-8.5 \mathrm{D}$, produced mature

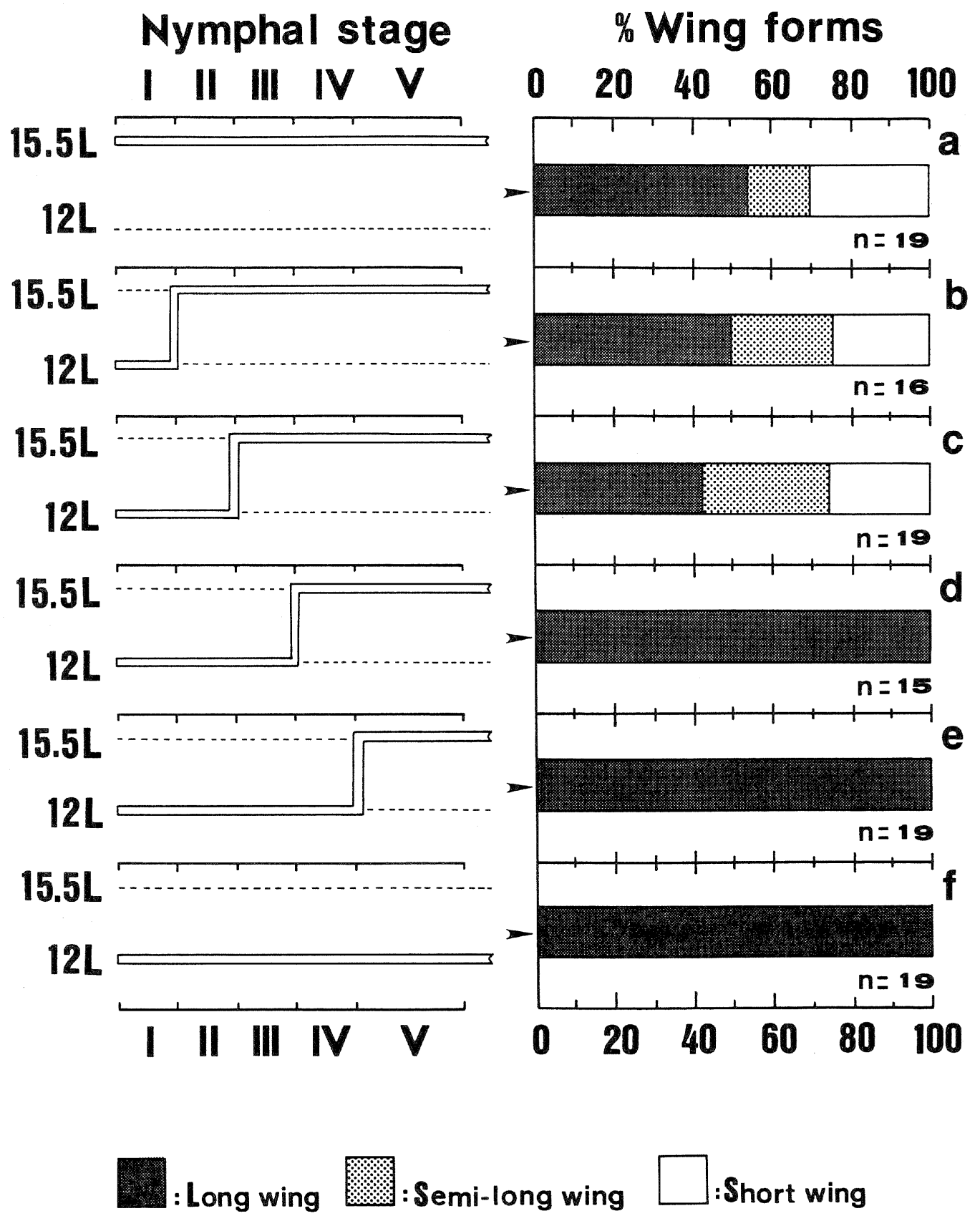

Fig. 2. Effect of transfer from $12 \mathrm{~L}-12 \mathrm{D}$ to $15.5 \mathrm{~L}-8.5 \mathrm{D}$ photoperiod during various instars on the induction of three wing-forms in $A$. paludum. Nymphs were transferred on the first day of new instars. Results of Fisher's exact probability test for the proportion of wing-forms: a versus b or $\mathrm{c}, P>0.05$; a versus d, e or $\mathrm{f}, P<0.05$. 


\section{Nymphal stage \%Wing forms \%Non-diapause}

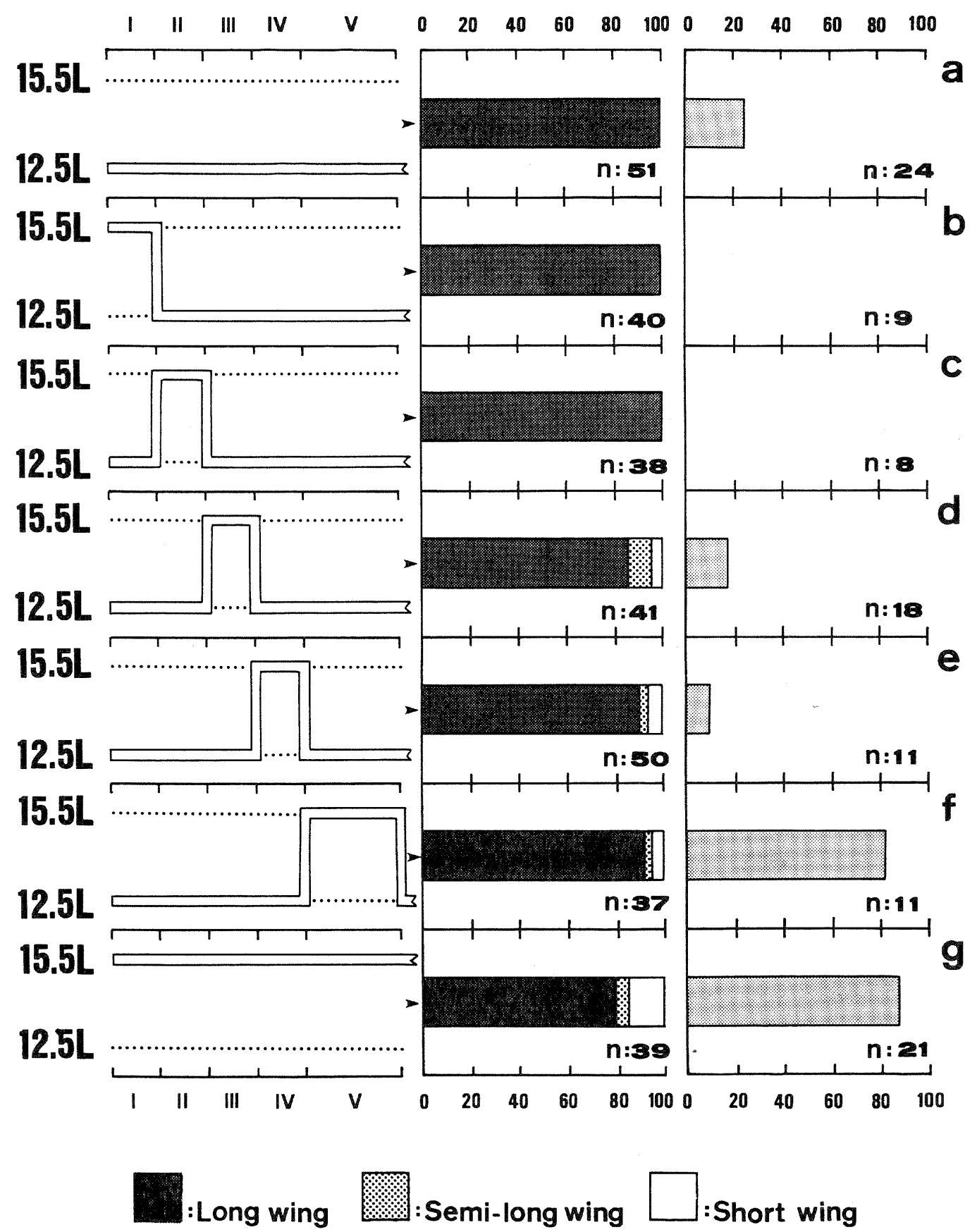

Fig. 3. Development into adults with each wing-form and reproductive maturation in Experiment 2 when the short-day photoperiod was set at 12.5L-11.5D in A. paludum. Results of Fisher's exact probability test for the proportion of wing-forms: a versus $b, c$ or $f, P>0.05$, a versus $d$, $\mathrm{e}$, or $\mathrm{g}, P<0.05$.

oocytes (Fig. 3f). The mean number of mature oocytes in the females of this group was $8.6( \pm 7.7: \mathrm{SD})$, similar to that $(10.1$ \pm 11.8 ) of the group exposed to $15.5 \mathrm{~L}-8.5 \mathrm{D}$ throughout maturation. Although only $27 \%$ of the females oviposited within 30 days after adult emergence, $60.7 \%$ of the females did so in the $15.5 \mathrm{~L}-8.5 \mathrm{D}$ control group. When nymphs were reared under 15.5L-8.5D only during the first two instars (Fig. 4b), the next two instars (Fig. 4c), or the fifth instar (Fig. 4d), most of the nymphs became long-winged adults, unlike the results of Experiment 3. This difference is due to the fact that the short day in Experiment 4 was $9.5 \mathrm{hr}$, shorter by $3 \mathrm{hr}$ than that in Experiment $3(12.5 \mathrm{hr})$. Half of the nymphs became shortwinged adults in the 15.5L-8.5D control group (Fig. 4e). 15.5L8.5D during the first two or the next two instars failed to induce 


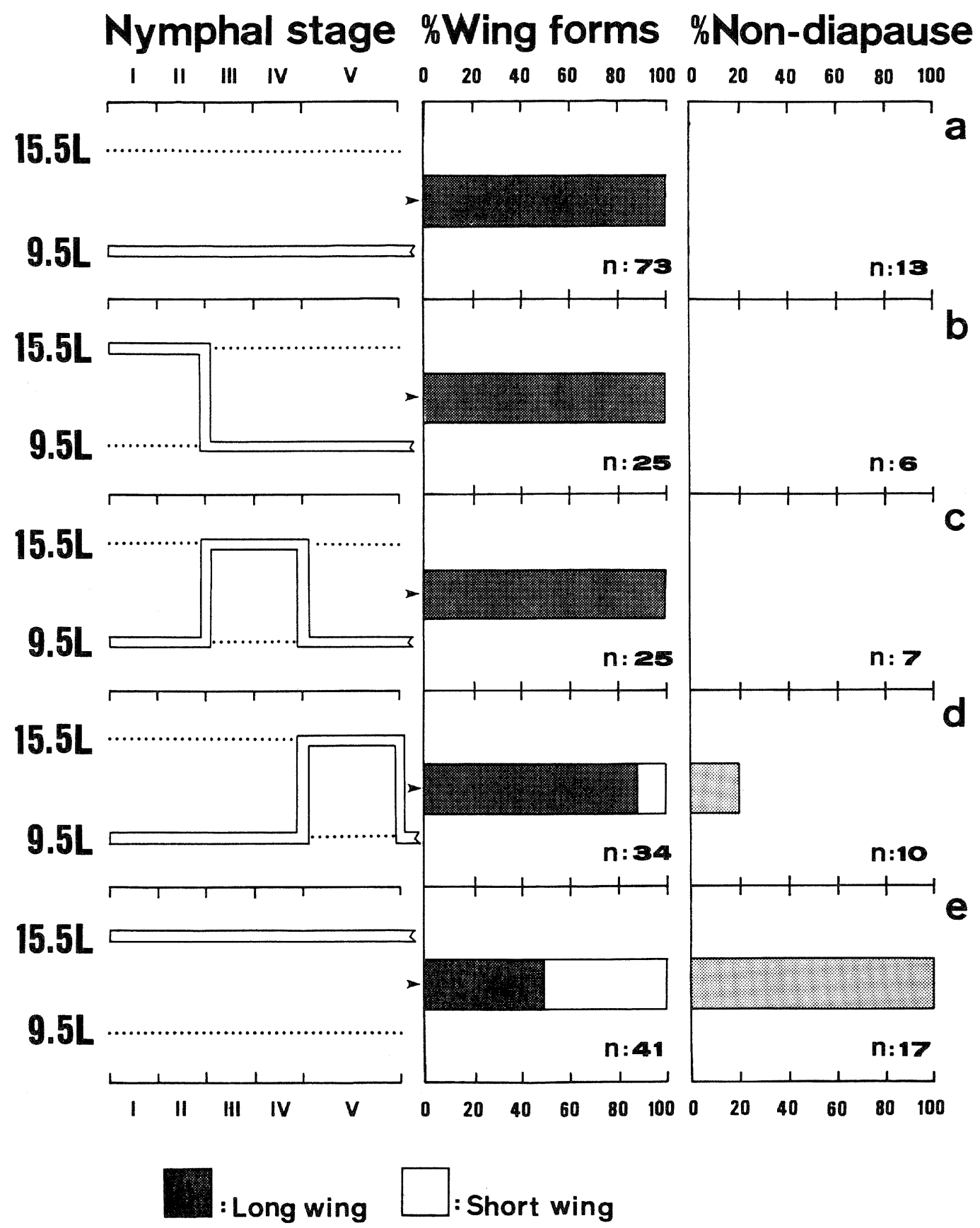

Fig. 4. Development into adults with each wing-form and reproductive maturation in Experiment 3 when 9.5L-14.5D was used in $A$. paludum. Results of Fisher's exact probability test: a versus $b, c$ or $d, P>0.05$; a versus $e, P<0.05$.

maturation of oocytes (Fig. 4b,c). Only two of the ten females had mature oocytes when they had been exposed to $15.5 \mathrm{~L}$ 8.5D during the fifth instar (Fig. 4d), unlike the results in Exp. 3. All of the females had, however, mature oocytes in the $15.5 \mathrm{~L}$ 8.5D control-group (Fig. 4e).

\section{DISCUSSION}

In Aquarius paludum, the photosensitive stages for the determination of wing form are mainly the third and fourth instars, because:

1. Long days until the end of the fourth instar or later induced many short-winged adults in Experiment 1 (Fig. 1).

2. Short days until the end of the third instar or later caused all the individuals to become long-winged adults in Experiment 2 (Fig. 2).

3. Long days at a specific stage of the third or fourth instar had a significant wing-shortening effect (Fig. 3).

Zera and Tiebel (1991) reported that the sensitive stage for the determination of wing-forms was restricted to the second 
instar in Limnoporus canaliculatus: 16L-8D and 12L-12D induced apterous and macropterous adults, respectively. Wing-pad development was strikingly different between the two wing forms in L. canaliculatus. This difference appears earlier in L. canaliculatus (at the beginning of the third instar or earlier) than in A. paludum (during the fifth instar) [Fig. 546 in Andersen (1982); Harada, unpublished]. In both species, the sensitive stage occurs mainly just before the stage at which the morphology of wing pads differentiates between the two wing-forms.

Aquarius paludum is the most sensitive in the last instar with respect to reproduction, as in other water striders, Gerris odontogaster (Kopfli et al., 1987) and G. comatus (Spence, 1989), and in other insects, such as Anopheles maculipennis (Vinogradova, 1960), Oncopeltus fasciatus (Dingle, 1974), and Anthocoris nemorum (Parker, 1975). However, relatively long durations of sensitivity were suggested in water striders Gerris buenoi and Limnoporus dissortis (Spence, 1989). The long sensitive stage for reproduction corresponds to that for wing form determination in these species and this correspondence fits to the Vepsäläinen's model (Vepsäläinen, 1978) that brachyptery and direct breeding (macroptery and diapause) are tightly linked according to the oogenesis-flight syndrome (Johnson, 1969) and that wing-form and reproduction are controlled by photoperiod in the same way. However, the present investigation revealed different sensitive stages for wing-form determination (the third and fourth instars) and reproduction (the fifth instar) in $A$. paludum, which suggests the tight linkage between wing-form and reproduction is not always the case.

In the present study, a long day photoperiod during either the third or fourth instar produced some short-winged adults, even when nymphs were reared during the rest of their nymphal stage under $12.5 \mathrm{~L}-11.5 \mathrm{D}$, a photoperiod near the critical one that is $13.75 \mathrm{~L}-10.25 \mathrm{D}$ for the populations in Kochi (Harada and Numata, 1993) (Fig. 3). This effect of long day photoperiod was, however, suppressed by the exposure to 9.5L-14.5D, which is much below the critical value, during the first and second instars (Fig. 4). Moreover, reproductive maturation caused by long days during the fifth instar was also inhibited by exposure during the rest of nymphal and adult stages to $9.5 \mathrm{~L}-14.5 \mathrm{D}$, but not by $12.5 \mathrm{~L}-11.5 \mathrm{D}$ (Figs. 3,4). The results suggest that various photoperiods are not detected merely as 'long days' or 'short days'. Both wing-form determination and reproductive diapause appear to be based on the quantitative assessment of photoperiodic information. Pieris brassicae (Lepidoptera) and Plautia stali (Heteroptera) also assess photoperiod quantitatively for the induction of diapause (Spieth and Sauer, 1991) and nymphal body coloration (Numata and Kobayashi, 1994), respectively. Also in the case of $A$. paludum, quantitative assessment is performed and this quantitative information is converted to 'all-or-none' responses as diapause vs non-diapause or longwing vs short-wing. However, it is not known where the quantitative information is converted to 'all-or-none' information in the effector system as described by Beck (1980), which could be at a photoperiod-accumulation-level, a neurosecretion level, an ecdysteroid or juvenile hormone level, or a hormone sensitivity level with respect to the effects on wing pads and the ovary. The conversion from the quantitative information to 'all-or-none' information should be clarified by future studies.

\section{ACKNOWLEDGMENTS}

We would like to thank Dr. Hideharu Numata, Department of Biology, Faculty of Science, Osaka City University, and Dr. John R. Spence, Department of Biological Sciences, University of Alberta, for critically reading this manuscript and giving us invaluable comments on it.

\section{REFERENCES}

Andersen NM (1982) The semiaquatic bugs (Heteroptera, Gerromorpha), phylogeny, adaptations, biogeography and classification. Entomonograph 3: 1-455

Andersen NM (1993) The evolution of wing polymorphism in water striders (Gerridae): a phylogenetic approach. Oikos 67: 433-443

Beck SD (1980) Insect Photoperiodism. 2nd ed, Academic Press, New York, pp 222-223

Dingle H (1974) Diapause in a migrant insect, the milkweed bug Oncopeltus fasciatus (Dallas) (Hemiptera, Lygaeidae). Oecologia 17: $1-10$

Harada T (1992) The oviposition process in two direct breeding generations in a water strider, Aquarius paludum (Fabricius). $J$ Insect Physiol 38: 687-692

Harada T (1993) Reproduction by overwintering adults of water strider, Aquarius paludum (Fabricius). Zool Sci 10: 313-319

Harada T, Taneda K (1989) Seasonal changes in alary dimorphism of a water strider, Gerris paludum insularis (Motschulsky). J Insect Physiol 35: 919-924

Harada T, Numata H (1993) Two critical day lengths for the determination of wing forms and the induction of adult diapause in the water strider, Aquarius paludum. Naturwissenschaften 80 : 430-432

Harrison RG (1980) Dispersal polymorphism in insects. Annu Rev Ecol Syst 11: 95-118

Johnson CG (1969) Migration and Dispersal of Insect by Flight. Methuen, London, pp 9-10

Kopfli R, Hauser R, Zimmermann M (1987) Diapausendetermination bei Wasserlaufern (Hemiptera, Gerridae). Rev Suisse Zool 94: 533-543

Numata H, Kobayashi S (1994) Threshold and quantitative photoperiodic responses exist in an insect. Experientia 50: 969971

Parker NJB (1975) The investigation of reproductive diapause in two British populations of Anthocoris nemorum (Hemiptera: Anthocoridae). J Entomol (A) 49: 173-178

Spence JR (1989) The habitat templet and life history strategies of pond skaters (Heteroptera: Gerridae): reproductive potential, phenology and wing dimorphism. Can J Zool 67: 2432-2447

Spence JR and Andersen NM (1994) Biology of water striders: interactions between systematics and ecology. Annu Rev Entomol 39: 101-128

Spieth HR, Sauer KP (1991) Quantitative measurement of photoperiods and its significance for the induction of diapause in Pieris brassicae (Lepidoptera, Pieridae). J Insect Physiol 37: 231238

Vepsäläinen K (1978) Wing dimorphism and diapause in Gerris: determination and adaptive significance. In "Evolution of Insect Migration and Diapause" Ed by H Dingle, Springer-Verlag, New York, pp 218-253 
Vinogradova EB (1960) An experimental investigation of the ecological factors inducing imaginal diapause in bloodsucking mosquitoes (Diptera, Culicidae). Ent Obozr 39: 327-340 (in Russian) Translation in Ent Rev 39: 210-219
Zera AJ, Tiebel KC (1991) Photoperiodic induction of wing morphs in the waterstrider Limnoporus canaliculatus (Gerridae: Hemiptera). Ann Entomol Soc Am 84: 508-516

(Received October 5, 1995 / Accepted October 22, 1996) 